\title{
Entrevista com o Professor Christopher Snow, do Toronto District School Board - TDSB - Ontario - Canadá
}

\author{
Interview with Professor Christopher Snow, of the Toronto District School Board - TDSB - Ontario - Canada
}

\section{Hércules Tolêdo Corrêa}

Universidade Federal de Ouro Preto - UFOP - Ouro Preto - Minas Gerais - Brasil

\begin{abstract}
$\longrightarrow$
Resumo: Entrevista com professor premiado da educação básica da província de Ontario, no Canadá. Christopher Snow é professor da Huron Public School, uma escola de ensino fundamental situada na região central de Toronto, na província de Ontario, Canadá. Pelo trabalho que tem desenvolvido junto às suas turmas, foi agraciado com um prêmio concedido pelo Primeiro-Ministro Justin Trudeau pelo seu Ensino de Excelência (ver https://www.ic.gc.ca/eic/site/pmate-ppmee.nsf/eng/wz02308.html).

Abstract: Interview with award-winning teacher of basic education in the province of Ontario, Canada. Christopher Snow is a professor at Huron Public School, an elementary school located in central Toronto, in the province of Ontario, Canada. For the work he has done with his classes, he was awarded an award by Prime Minister Justin Trudeau for his Teaching of Excellence (see https://www.ic.gc.ca/eic/site/pmateppmee.nsf /eng/wz02308.html).
\end{abstract}

\section{Introdução}

Christopher Snow é professor da Huron Public School, uma escola de ensino fundamental situada na região central de Toronto, na província de Ontario, Canadá. Pelo trabalho que tem desenvolvido junto às suas turmas, foi agraciado com um prêmio concedido pelo Primeiro-Ministro Justin Trudeau pelo seu Ensino de

\section{Excelência}

(ver

https://www.ic.gc.ca/eic/site/pmate-

ppmee.nst/eng/wz02308.html).

De acordo com o site governo canadense, Christopher Snow constrói seu ensino em torno da busca da justiça social e da equidade de gênero dentro da sala de aula e no mundo. O professor começa cada dia com um trabalho de reconhecimento de terras indígenas para mostrar às crianças o que é necessário para povos indígenas e não-indígenas construírem uma visão comum. Numa abordagem interdisciplinar, Snow procura cultivar a curiosidade intelectual de seus alunos e, ao mesmo tempo, aprimorar suas habilidades analíticas orais e de leitura e escrita, para que possam se tornar cidadãos globais e em condições de competir no mercado de trabalho. $\mathrm{Na}$ sala de aula, aproveita a tecnologia digital para mostrar às crianças como responder a grandes questões globais e sociais e desenvolver habilidades: as crianças pesquisam e analisam dados on-line, além de aprender a ler tabelas e gráficos, escrever colaborativamente, fotografar, redigir e enviar e-mails adequados e educados. Mr. Snow também projeta atividades práticas e interdisciplinares para envolver os jovens alunos: por exemplo, três alunos usaram matemática, leitura, redação, pesquisa, ciências e habilidades sociais para realizar uma eco-auditoria em sala de aula. A atividade teve tanto sucesso que uma auditoria semelhante foi realizada em várias escolas canadenses.

Chris Snow também se esforça para implementar o chamado da Comissão de Verdade e Reconciliação para descolonizar o currículo, fazendo com que os alunos aprendam sobre o sistema de 
escolas residenciais por meio de pesquisa, aprendizagem experiencial e redação. Snow se serve da justiça social para apresentar aos alunos temáticas como direitos humanos e proteção ambiental e, depois, por meio de atividades baseadas em pesquisa (inquirybased learning), identificam barreiras e desafios, além de examinarem possíveis soluções e considerarem seus papéis como jovens na promoção da mudança.

Chris Snow, como é carinhosamente chamado pelos mais próximos, foi também um dos poucos professores do conselho convidados a participar de dois programas de desenvolvimento profissional de longo prazo para trabalhar com idosos e especialistas em educação indígena para trazer mais conhecimento e cultura indígena para as escolas. Foi também convidado pelo Conselho de Canadenses para fazer parte de uma delegação de professores de Ontario que viajou para o Chile no verão de 2017 para estudar a ética de investir no sistema de água chileno. Snow também supervisiona o desenvolvimento profissional baseado na escola, trabalhando com o diretor para definir a agenda para o desenvolvimento de professores em toda a escola, metas e planos de ação.

Hércules Tolêdo Corrêa é professor e pesquisador da Universidade Federal de Ouro Preto e líder do grupo de pesquisa MULTDICS Multiletramentos e usos das TDIC em Educação. Esteve em Toronto, no Canadá, no segundo semestre de 2017 e primeiro semestre de 2018, em estágio de pós-doutoramento sob a supervisão da professora e pesquisadora Doutora Heather Lotherington, da Faculty of Education da York University. Neste período, desenvolveu pesquisa sobre multiletramentos e multiculturalidade em escolas públicas de ensino fundamental. Dentre os trabalhos realizados, acompanhou aulas do Professor Christopher Snow e realizou a entrevista que segue aqui publicada, sobre o trabalho que vem realizando. Em janeiro de 2019, publicou na revista Signo, v. 44, n. 79, entrevista com a Dra. Lotherington e a diretora aposentada de escola básica canadense Cheryl Paige, sobre o trabalho delas à frente da Joyce Public School, escola da periferia de Toronto que se tornou referência no ensino na perspectiva dos multiletramentos e cultura digital.
HÉRCULES CORRÊA (HC): Mr. Snow, eu gostaria que você falasse um pouco sobre o trabalho desenvolvido aqui nesta escola, Huron Public School, com as chamadas metodologias ativas (Project-based learning, Problem-based learning, Inquiry-based learning). Como é que você chegou a essas abordagens de ensino e de aprendizagem e como tem sido aplicá-las com os seus alunos? Você recebeu uma formação específica para realizar esse trabalho? Existe uma diferença entre essas formas de trabalho com a educação?

CHRISTOPHER SNOW (CS): Estamos numa escola pública e no estado de Ontario temos uma mesma filosofia de ensino em todas as escolas. Nós estamos mudando o processo de educação. Por exemplo: há alguns anos, usávamos uma pedagogia mais tradicional, como no mundo inteiro. Uma pedagogia estruturada pelos professores. Um sistema em que os professores decidiam o que os alunos iriam fazer. Mas agora a pedagogia está mudando. Eu estou trabalhando com os meus alunos para decidir o que eles vão fazer. Eu acredito que as crianças, em geral, já sabem como aprender. Eu não preciso ensinar a elas como aprender. Isso é natural para as crianças. Eu preciso dar oportunidades para que elas aprendam. Por exemplo, eu tenho a possibilidade de incrementar o currículo do estado. Eu tenho o currículo estadual, mas eu pergunto aos meus alunos o que eles querem fazer, o que eles querem aprender a partir do currículo e eles têm a oportunidade para escolher o que querem aprender, como eles vão aprender, o que querem fazer depois, como eles vão comunicar o que aprenderam. Eu preciso dar essas oportunidades para os meus alunos. Eu não vejo grande diferença entre a aprendizagem baseada em problema, projeto ou investigação. A questão é: eu não tenho o poder para decidir o que vai acontecer na aula. Eu divido essa responsabilidade com meus alunos. Eles são ainda crianças e eu preciso fazer muito para criar um espaço para aprender assim. Eu preciso fazer muita coisa para estruturar, mas eu estou dividindo essa responsabilidade com meus alunos. 
HÉRCULES CORRÊA: Professor Snow, eu gostaria de falar sobre o prêmio que você recebeu do primeiro-ministro do Canadá em reconhecimento ao seu trabalho como professor na Elementary School aqui na província.

CHRISTOPHER SNOW: Todos os anos o primeiro-ministro concede um certificado para os professores do Canadá que estão mudando a pedagogia, fazendo coisas originais para melhorar nossa educação. Eu estou muito feliz em receber este certificado. Para mim é muito importante. Normalmente, falamos que nós, professores, estamos sempre aprendendo. Eu estou sempre ensinando e ao mesmo tempo aprendendo. É muito importante sempre lembrar que os professores precisam ser os primeiros alunos na sala de aula.

HÉRCULES CORRÊA: Mr. Snow, gostaríamos também de saber um pouco sobre a sua trajetória de formação acadêmica e também conhecer um pouco mais das suas experiências com a educação. Por quais escolas passou aqui em Toronto e como se caracterizam essas escolas?

CHRISTOPHER SNOW: Eu estudei na University of Toronto e na York University, aqui em Toronto também, e comecei a lecionar quando tinha 25 anos, em 1996. Durante meu processo de formação, estudei muitas teorias da educação, mas nessa época estava tudo muito diferente nas escolas. Havia uma educação mais tradicional e depois de nove ou dez anos eu vi pela primeira vez a ideia de aprendizagem baseada em projetos. No início da minha carreira, eu estava muito interessado em leitura. Fiz uma especialização em leitura e fui por quase nove anos consultor do Ministério da Educação. Eu trabalhava com formação de outros professores com ensino de leitura. Estava muito interessado no processo de aprendizagem dos alunos e no mesmo processo para os professores. Depois, quando voltei para a sala de aula da Elementary School, em 2009 e 2010, eu comecei de novo aprendendo como ensinar. Pela primeira vez eu combinei o que eu sabia sobre como ensinar a leitura com a ideia de dividir a responsabilidade com os alunos. Fiz muitos cursos no âmbito do meu trabalho. Acredito que seja muito importante aprender para os profissionais que estão dentro da sala de aula. Fui muitas vezes para o centro de educação para os professores dentro do Toronto District School Board. Fiz muitos cursos, visitei muitas vezes outras escolas para conversar com os outros professores que estão interessados na Project-based learning. Tenho amigos e colegas aqui na escola com os quais converso sempre sobre como fazer, como incrementar, como melhorar a pedagogia do Inquiry-based learning. Eu não fiz um mestrado ainda. Mas eu fiz muitos cursos profissionais na Universidade e eu estou ensinando em alguns cursos também. Esse processo para mim é muito importante para aprender porque quando eu estou ensinando outras pessoas eu estou aprendendo também.

HÉRCULES CORRÊA: Professor Snow, sobre essas escolas pelas quais você passou antes de chegar a essa, são escolas muito diferentes ou elas têm mais semelhanças com essa?

CHRISTOPHER SNOW: São muito diferentes. Nos primeiros anos, quando comecei a ensinar, eu trabalhava em escolas muito pobres, nas áreas de divisa de Toronto e eu aprendi como ensinar em condições muito difíceis, com alunos que têm muita pobreza em casa, muitos problemas sociais. Aprendi muito como aprender sobre minha cultura e como minha cultura é feita, a pedagogia, as ideias e sobre o que é a educação e aprendi muito da cultura dos alunos e acho que é muito importante e se a gente quer incluir os alunos no processo de educação, a gente precisa aprender muito sobre o que eles são e das culturas, das línguas, a gente precisa saber o que acontece nas casas, nas vidas deles e a gente precisa criar um espaço na sala de aula em que todos os alunos podem ser o que eles são complemente. Acredito que isso seja muito importante para a aprendizagem.

HÉRCULES CORRÊA: Uma característica de Toronto como um todo, e essa característica se reflete na escola, é essa questão multicultural. Então é muito comum nas escolas de Toronto encontrar alunos que não são falantes de inglês como primeira língua e sim como segunda língua. Aqui nessa escola, como é que você vê essa questão? Atualmente, você está 
trabalhando com alunos de 9, 10 anos. Mas há momentos também, eu já tive oportunidade de ver, que você fica com os alunos menores. Há muitos alunos aqui com dificuldades muito grandes com o inglês, como é essa questão?

CHRISTOPHER SNOW: A diversidade linguística é muito comum aqui, eu vou dizer que é muito como em todas as escolas de Toronto e também é uma característica nacional do Canadá. Eu acho que muito bom receber aqui essa pluralidade de línguas. É muito comum aqui em Toronto encontrarmos alunos que ainda estão aprendendo o inglês e a gente tem uma vantagem, uma coisa boa, que é os alunos trazerem suas "línguas de casa" para a escola. Não é necessário falar o inglês fluentemente para aprender. Como eu disse há pouco, as crianças em geral sabem como aprender e isso também é verdade para os alunos que estão aprendendo inglês. Nós temos os professores específicos para ensinar os alunos que não falam inglês, no início. Hoje tenho três ou quatro alunos na sala de aula que estão aprendendo inglês. Acho que tenho dois alunos no nível básico e dois outros que estão no nível intermediário. Na sala de aula às vezes eles estão escrevendo, lendo na primeira língua, outras vezes eles estão escrevendo em inglês e eles têm essa flexibilidade para usar a primeira língua para aprender quando eles estão aprendendo o inglês. As pesquisas dizem que é muito importante para os alunos usar as primeiras línguas para aprender quando eles estão aprendendo o inglês e eu facilito essas oportunidades todo dia na sala de aula. Eu acho que é muito importante porque não necessário é pensar em inglês. As crianças precisam pensar em qualquer língua e é necessário usar a língua mais forte para eles, a sua primeira língua, até melhorarem o inglês.

HÉRCULES CORRÊA: Eu gostaria de conversar um pouco agora, professor Snow, sobre a entrada de trabalho no magistério aqui no Canadá. Como é que se dá esse processo. Eu gostaria de saber duas coisas, primeiro sobre como é essa entrada, como é a seleção de professores para trabalhar no sistema público e gostaria de saber se há uma estabilidade no emprego desses professores, como que isso funciona aqui no Canadá?

CHRISTOPHER SNOW: Há um processo dentro do Toronto District School Board para selecionar, por meio de uma entrevista. Durante essa entrevista os diretores das escolas fazem quatro ou cinco perguntas básicas para saber o que os professores sabem de pedagogia, como organizar a sala de aula, como trabalhar com os alunos com dificuldades, por exemplo, os alunos que estão aprendendo inglês, eles querem saber como os professores podem trabalhar com a comunidade e com os outros colegas. Geralmente eles têm cinco perguntas para todo mundo que quer ser professor, isso faz parte do processo. Após a entrevista os diretores ouvem as experiências profissionais, as experiências com alunos ou com as crianças, mas as outras experiências também são valorizadas, por exemplo, se você é uma enfermeira e se você muda de trabalho, valorizado as pessoas que têm experiências vocacionais, em outras áreas. Numa terceira fase, os diretores conversam com outros profissionais que conhecem o professor para ouvir o que as outras pessoas pensam e a partir daí, dessas três fases, eles selecionam os professores. Há épocas em que a gente precisa de mais professores e há outras em que não existe demanda. Sobre a estabilidade no trabalho, posso dizer que temos um sindicato muito forte, quase o mais forte do país, para os professores. Nosso trabalho é muito valorizado, o sistema é muito valorizado aqui e a gente tem um salário muito bom para os professores. Existe uma cultura da educação e a gente tem essa ideia de que a educação pública é muito importante para criar uma sociedade mais igualitária, para diminuir a desigualdade. Há problemas, com certeza, há muitas pessoas que não acreditam, mas em geral eu acho que mais de noventa por cento das crianças aqui vão para uma escola pública e nosso sindicato reivindica muito para manter o salário dos professores num bom patamar, porque a profissão é muito valorizada. Nós temos boas condições de trabalho, porque nossas condições do trabalho são também as condições de 
aprendizagem para os alunos. Se eu valorizo 0 professor, estou valorizando também o aluno.

HÉRCULES CORRÊA: Pelo que pude observar, os professores trabalham em horário integral, são quarenta horas de trabalho semanais?

CHRISTOPHER SNOW: Quarenta horas mais ou menos na escola e a gente tem algumas coisas para fazer em casa. Como eu tenho cerca de 24, 25 anos de trabalho, tenho bastante experiência e consigo fazer muitas coisas mais rapidamente. Mas precisamos trabalhar em casa para preparar as aulas, para escrever as atividades para os alunos, para estudar

HÉRCULES CORRÊA: Embora vocês tenham dentro do horário na escola também momentos de planejamento, de preparação, não é isto?

CHRISTOPHER SNOW: Quarenta minutos por dia, entre quarenta e cinquenta minutos por dia para preparar. O sindicato brigou muito por esse direito durante uns vinte anos. Se você quiser fazer as coisas bem feitas, você precisa de tempo para preparar, agora temos este tempo.

HÉRCULES CORRÊA: Outra questão que gostaria de abordar é, no Brasil, a gente percebe que há uma feminização do magistério e, principalmente nesse nível, que no Brasil nós chamamos de Ensino Fundamental, que aqui é o Elementary School, e também na Educação Infantil, o antigo Jardim da Infância, o famoso Kindergarten, há uma imensa maioria de mulheres no magistério, parece que aqui no Canadá não é tanto assim.

CHRISTOPHER SNOW: Na verdade, aqui no Canadá é um pouco assim também. Esta escola, a Huron Public School, é diferente, eu nunca vi uma escola assim. A gente tem muitos homens aqui nessa escola, quase quarenta por cento. Mas no sistema educacional inteiro está diminuindo esse percentual. Acredito que esteja em mais ou menos vinte por cento entre quinze e vinte por cento na Elementary School. Eu disse que a profissão é valorizada, mas eu acho que não é valorizada suficientemente porque não é um trabalho só para as mulheres. A gente tem muitos mais homens no ensino secundário, na High School. Mas nas escolas fundamentais está diminuindo a quantidade de homens. Há vinte anos estava a quase trinta por cento, mas está diminuindo de novo e o estado não tem estratégias para mudar isso. Mas eu penso que é muito importante para a sociedade em geral porque, por exemplo, eu quero mostrar para meus alunos que eu sou um homem e sou uma pessoa cuidadosa, quero mostrar muitas maneiras de ser para os alunos para mudar essa ideia de que há atividades e profissões mais adequadas a determinado gênero.

HÉRCULES CORRÊA: Professor Snow, tenho pesquisado a chamada Pedagogia dos Multiletramentos. Gostaria de saber se você conhece esse trabalho por meio de suas formações...

CHRISTOPHER SNOW: $\mathrm{Na}$ verdade, não conheço muito sobre essa pedagogia, mas acredito que se aproxima muito de coisas que tenho feito. Acredito que haja muitos caminhos para aprender. As crianças podem aprender de maneira diferente porque as mentes funcionam de maneira diferente. Nem todos aprendem da mesma maneira. É preciso também pensar nas individualidades.

HÉRCULES CORRÊA: Prof. Snow, quero reafirmar que fiquei muito feliz em conversar com você e que vou poder divulgar um pouco seu trabalho engajado e exitoso como professor. Fico muito feliz de poder compartilhar isso com a comunidade escolar e acadêmica lá do Brasil por meio dessa entrevista. Agradeço muitíssimo a sua disponibilidade e se você quiser acrescentar mais alguma coisa, fique à vontade.

CHRISTOPHER SNOW: Só quero dizer muito obrigado pela oportunidade de explicar, conversar, e desculpar pelo meu português.

O Professor Christopher Snow, por interesse linguístico, mas também por questões pessoais e afetivas, aprendeu português sem nunca ter frequentado aulas específicas para isso! Ao editar esta entrevista, procurei um ponto de equilíbrio entre a linguagem mais informal e a mais formal, nesse continuum que é a oralidade-escrita de qualquer língua. Também gostaria de registrar aqui o meu agradecimento ao Prof. Snow, que abriu sua sala de aula para um pesquisador brasileiro conhecer de perto um pouco mais da realidade do ensino canadense e trazer isso para o Brasil, por meio das minhas 
discussões no âmbito da formação inicial e continuada

de professores da área de linguagens.

Ouro Preto, 23 de janeiro de 2020.

CORREA, Hércules Tolêdo. ENTREVISTA COM O PROFESSOR CHRISTOPHER SNOW - TORONTO DISTRICT SCHOOL OF BOARDS. Signo, Santa Cruz do Sul, v. 45, n. 84, nov. 2020. ISSN 1982-2014. Disponível em: <https://online.unisc.br/seer/index.php/signo/article/view/15352>. doi:https://doi.org/10.17058/signo.v45i84.15352. 